\title{
EBV-positive large B-cell lymphoma with an unusual intravascular presentation and associated haemophagocytic syndrome in an HIV-positive patient: report of a case expanding the spectrum of EBV-positive immunodeficiency-associated lymphoproliferative disorders
}

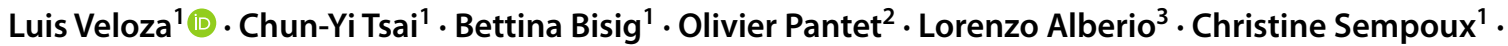 \\ Matthias Cavassini ${ }^{4}$ - Laurence de Leval ${ }^{1}$
}

Received: 22 April 2021 / Revised: 31 May 2021 / Accepted: 10 June 2021 / Published online: 19 June 2021

(c) The Author(s) 2021

\begin{abstract}
Intravascular large B-cell lymphoma is a rare and aggressive EBV-negative large B-cell lymphoma with a dismal outcome. Here, we describe the case of a 76-year-old HIV-positive patient with an acute presentation of systemic symptoms and rapidly fatal outcome. Autopsy revealed a disseminated large B-cell lymphoma with an intravascular distribution involving the liver, lymph nodes, spleen, and bone marrow and associated to fibrin thrombi in hepatic capillary haemangiomas. The neoplastic B cells (CD79a +/-, CD20+/-, CD30 +, MUM1 +, PD-L1 +) showed a Hodgkin and Reed-Sternberg-like morphology and were EBV-positive with a latency type II (LMP1 +, EBNA2-). Haemophagocytosis was documented in the bone marrow and lymph nodes. This case illustrates the diagnostic challenges of large B-cell lymphoma with intravascular presentation. We found only five other cases of EBV-positive large B-cell lymphoma with an intravascular presentation in the literature, three of which had an underlying immunodeficiency adding to the broad spectrum of EBV-associated lymphoma in the setting of immunosuppression.
\end{abstract}

Keywords Intravascular large B-cell lymphoma $\cdot$ EBV $\cdot$ Hepatic capillary haemangioma $\cdot$ HIV $\cdot$ Haemophagocytic syndrome

Laurence De Leval

Laurence.deLeval@chuv.ch

1 Institute of Pathology, Department of Laboratory Medicine and Pathology, Lausanne, University Hospital (CHUV) and Lausanne University (UNIL), Rue du Bugnon 25, CH-1011 Lausanne, Switzerland

2 Service of Adult Intensive Care, Lausanne University Hospital (CHUV) and Lausanne University (UNIL), Lausanne, Switzerland

3 Service and Central Laboratory of Hematology, Department of Oncology and Department of Laboratory Medicine and Pathology, Lausanne University Hospital (CHUV) and Lausanne University (UNIL), Lausanne, Switzerland

4 Service of Infectious Diseases, Department of Medicine, Lausanne University Hospital (CHUV) and Lausanne University (UNIL), Lausanne, Switzerland

\section{Introduction}

Intravascular large B-cell lymphoma (IVLBCL) is a rare and aggressive B-cell neoplasia that affects mainly elderly patients, usually disseminated at diagnosis and characterized by the selective growth of neoplastic cells within the lumina of vessels, particularly the capillaries [1]. The disease usually affects individuals without underlying immunodeficiency and is Epstein-Barr virus (EBV)-negative [2]. Three variants of clinical presentation are currently recognized as follows: (1) a classical form (usually encountered in Western countries), which shows organ-related symptoms with frequent central nervous system and cutaneous involvement; (2) a haemophagocytic syndrome (HPS)-associated form (Asian variant) characterized by fever, hepatosplenomegaly, pancytopenia, and multiorgan failure; and (3) a cutaneous variant, associated with better outcome [2]. Here, we report a 76-year-old human immunodeficiency virus 

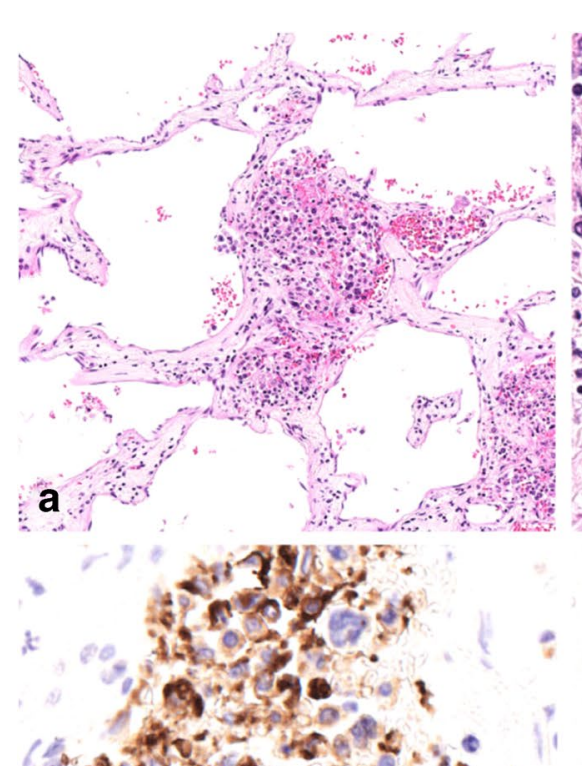

chate. te.
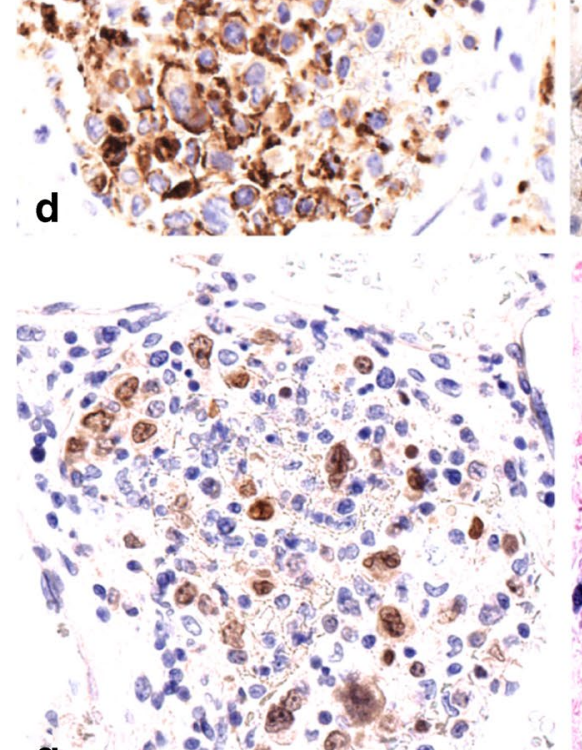

g $t^{\circ}$

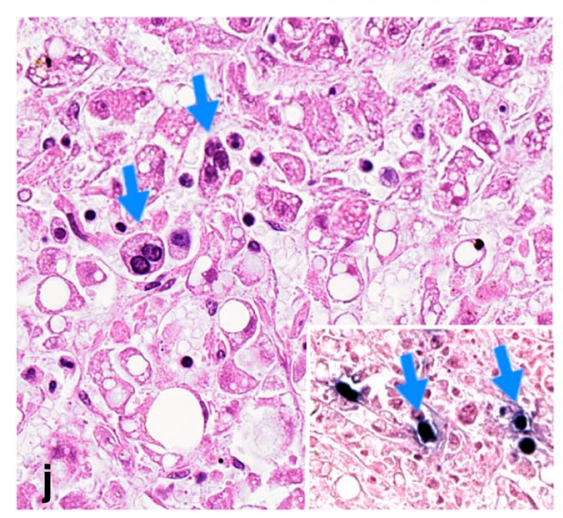

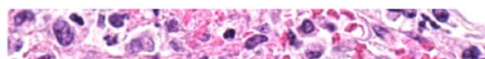

10. 0.0 . 100

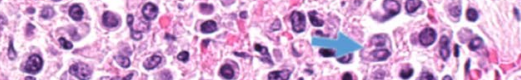

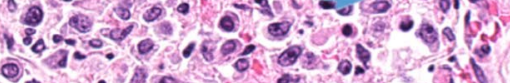

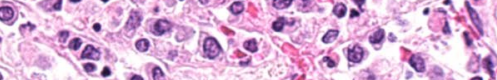

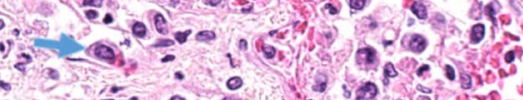

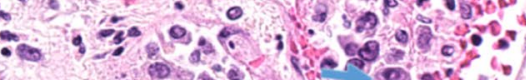

o) 20.080 .45

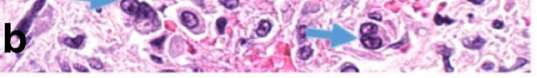

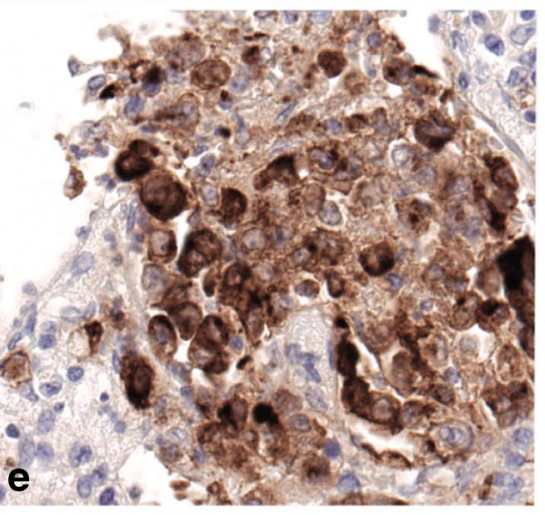

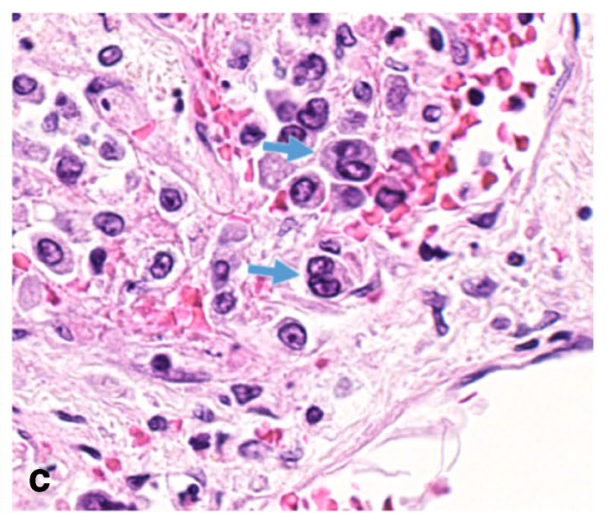

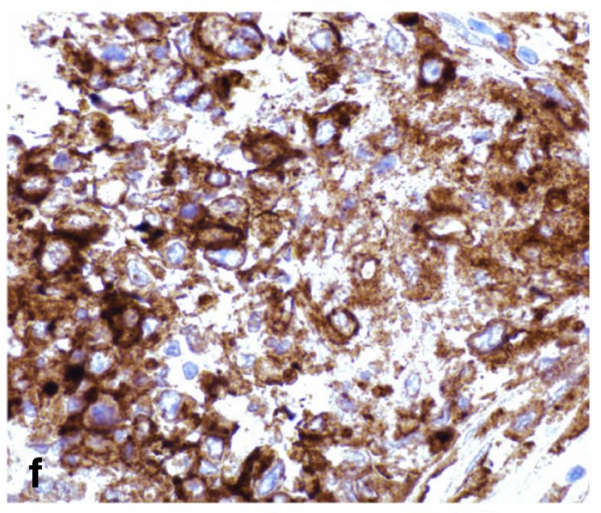

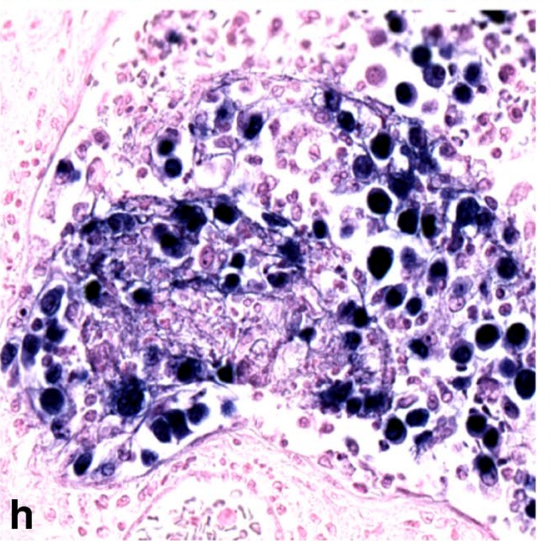
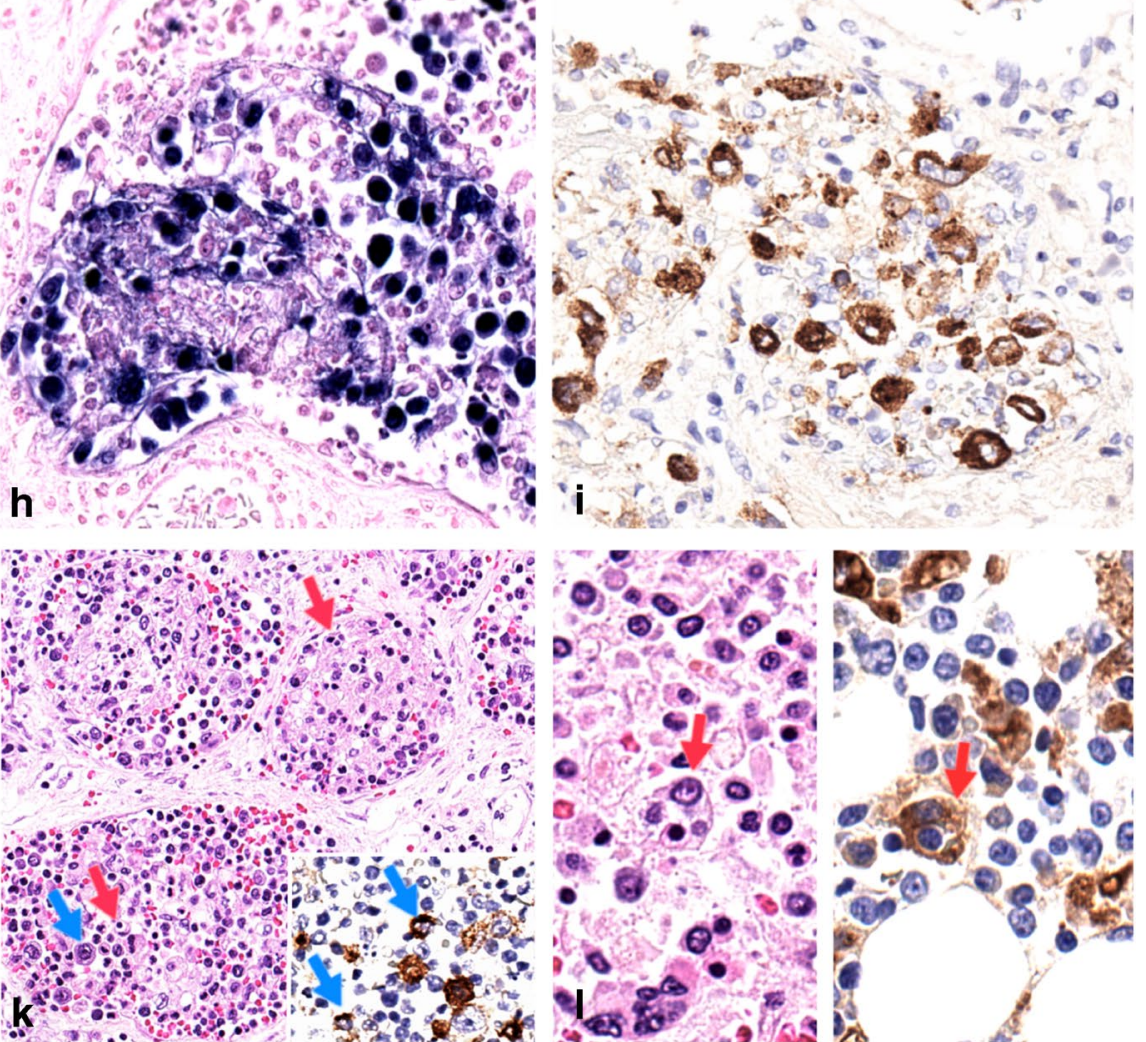

$0: 00^{\circ}-10$ D \%०:1300\%

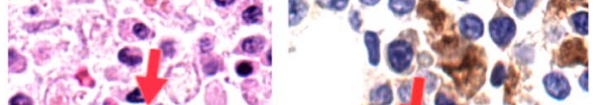

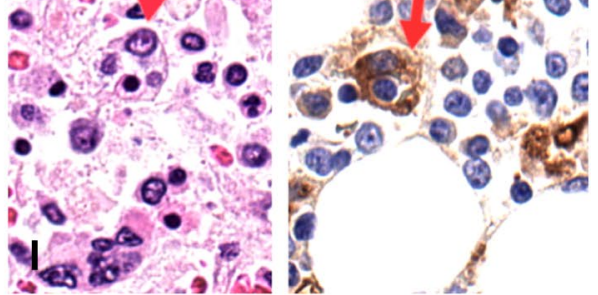

(HIV)-positive patient with a post-mortem diagnosis of EBV-positive large B-cell lymphoma with an unusual intravascular presentation. Interestingly, tumour cells invaded the lumina of hepatic capillary haemangiomas. We found five other cases of EBV-positive large B-cell lymphoma with an intravascular location in the literature. Collectively, these 
४Fig. 1 Histopathologic features of liver (a-j), lymph nodes (k), and bone marrow (l). Liver haemangioma showed aggregates of large tumour cells admixed to fibrin thrombi in the vascular lumina (a). The lymphoma cells were large pleomorphic sometimes resembling Reed-Sternberg cells (b, arrows, and $\mathbf{c}$ ). The tumour cells were partially positive for CD20 (d), strongly positive for CD30 (e), PD-L1 (clone SP263) (f), and MUM1 (g). Neoplastic cells were positive for EBV (EBER-ISH) (h) and LMP1 (i). Atypical EBV-positive large tumour cells were identified in hepatic sinusoids ( $\mathrm{j}$, arrows; EBERISH, inset, arrows). Tumour cells were also observed colonizing lymph node's blood vessels (k, blue arrow), with LMP1-expression (k, inset, blue arrows). Lymph node's blood vessels (k) and bone marrow (l, left panel) comprised many histiocytes with engulfed red blood cells or nucleated cells (red arrows). CD68 (clone PG-M1) immunostaining highlights haemophagocytic histiocytes (l, right panel, red arrow). Original magnifications: $\mathbf{a} \times 100, \mathbf{b}, \mathbf{d}, \mathbf{e}, \mathbf{f}, \mathbf{g}, \mathbf{h}, \mathbf{i}$, $\mathbf{j}, \mathbf{l} \times 400, \mathbf{k} \times 200, \mathbf{c} \times 600$

case reports emphasize the broad spectrum of EBV-associated lymphoproliferative disorders and a possible oncogenic role of EBV and immunosuppression in these rare instances.

\section{Case presentation}

The patient was a 76-year-old Caucasian male known for HIV infection diagnosis 2 years ago in the Caribbean who started combined anti-retroviral therapy at diagnosis. The patient with recent onset of fatigue and $30 \mathrm{~kg}$ weight loss was admitted to the emergency department with altered general condition and fever $\left(38^{\circ} \mathrm{C}\right)$. He reported having interrupted the treatment for a couple of months. Abdominal sonography revealed hepatomegaly with some hypodense foci measuring up to $2 \mathrm{~cm}$, consistent with hepatic haemangiomas. No lesion suspicious of neoplasia was observed. At admission, laboratory tests showed low CD4 + T-cell count, 83 cells $/ \mathrm{mm}^{3}$; HIV viral load, $4.1 \times 10^{3}$ copies $/ \mathrm{ml}$; Hb $92 \mathrm{~g} / \mathrm{l}$; leukocytes $4.4 \times 10^{9} / \mathrm{L}$ with lymphopenia at $0.6 \times 10^{9} / \mathrm{L}$; platelets $113 \times 10^{9} / \mathrm{L}$; ferritin $8.033 \mu \mathrm{g} / 1$ (normal values: 24 to $336 \mu \mathrm{g} / \mathrm{l})$; fibrinogen $<1.5 \mathrm{~g} / \mathrm{L}(2.0$ to $4.0 \mathrm{~g} / \mathrm{L})$ and normal values of triglycerides $(<150 \mathrm{mg} / \mathrm{dL})$. A high EBV viral load (400.000 copies/mL) suggested the possibility of a HPS, although in the course of the hospitalization only four of five criteria required for the diagnosis were met (fever, anaemia and thrombocytopenia, hypofibrinogenemia and high ferritin levels). Repeated haemocultures and multiple serologies remained negative. Despite antiretroviral therapy, broad-spectrum antibiotic and antifungal therapy, patient developed acute liver and renal failure, refractory vasoplegic shock, and died 5 days after admission.

The autopsy showed pericardial and pleural effusions, haemorrhagic ascites, splenomegaly (530 g), and hepatomegaly (2000 g). Two haemorrhagic-appearing lesions $(2.4$ and $3 \mathrm{~cm})$ in the liver consistent with haemangiomas suspected by imaging studies were found. Small intra-abdominal and supra-diaphragmatic lymph nodes $(<1 \mathrm{~cm})$ were identified.

Histologically, the liver lesions were typical of capillary haemangiomas and consisted of large vascular spaces lined by unremarkable endothelium. The lumina contained aggregates of large, atypical tumour cells with ample and pale cytoplasm, irregular nuclear contours, vesicular chromatin, some with prominent nucleoli or Reed-Sternberglike morphology (Fig. 1a-c), often admixed with fibrin thrombi. The atypical large cells were partially positive for CD20 (Fig. 1d), and CD79a, strongly positive for CD30 (Fig. 1e) and PD-L1 (Fig. 1f) and partially expressed MUM1 (Fig. 1g). CD10, BCL6, CD138, LANA1 (HHV8), CD5, and MYC were negative. KI-67 proliferation index was around $60 \%$. Virtually all tumour cells were positive for EBV by in situ hybridization with EBER probes (Fig. 1h) and by immunohistochemistry were LMP1-positive (Fig. 1i) and EBNA2-negative. Intravascular EBV-positive tumour cells were observed in the hepatic sinusoids outside the hepatic hemangioma (Fig. 1j), lymph nodes sinuses and small and medium-sized blood vessels (Fig. 1k), spleen, and bone marrow. Numerous histiocytes with abundant cytoplasm and ingested red blood cell, erythroid progenitors, or lymphocytes (haemophagocytosis) were identified in the lymph nodes' blood vessels (Fig. 1k), liver, and bone marrow (Fig. 11, left panel) highlighted by CD68 (Fig. 11, right panel). No lesions of Kaposi's sarcoma were observed. FISH studies using break-apart probes did not detect rearrangements of BCL2, BCL6, or MYC. High-throughput sequencing analysis using a customized panel of 54 genes relevant to the biology of mature B-cell lymphoma (Supplemental Information) did not detect mutations in MYD88, CD79a, or $E Z H 2$, genes recurrently altered in IVLBCL [2]. Multiple mutations suggestive of aberrant somatic hypermutation were detected at low variant allele frequency (3\%) in the of SOCS1 exon 2.

\section{Discussion}

Here, we report a case of an EBV-positive large B-cell lymphoma with an unusual intravascular presentation, which manifested as a clinically fulminant disease in a deeply immunosuppressed patient with uncontrolled HIV infection. Similar to typical IVLBCL, the diagnosis was made postmortem, highlighting the difficulties in reaching a timely diagnosis in these patients [1]. The HPS suspected clinically was convincingly confirmed by the histological findings at autopsy, and other characteristic findings of HPS-associated variant of IVLBCL were also observed [2], i.e., bone marrow involvement, fever, hepatosplenomegaly, and thrombocytopenia, which were present in our patient. Nevertheless, the HPS-associated variant of IVLBCL has been reported 
almost exclusively in Asian patients without associated immunosuppression or EBV infection [2, 3]. Therefore, it can be reasonably suggested that EBV infection may have played a role in the development of florid HPS in our patient.

We identified five other cases of EBV-positive large B-cell lymphoma with an unusual intravascular presentation reported in the literature, whose clinicopathological characteristics are shown in Table 1 [4-8]. These occurred in four men and one woman at a median age of 57 years (range 42-65 years). The four patients with documented ethnicity were Asian, in contrast to the Western origin of our case. Interestingly, three of the five patients had underlying immunosuppression (HIV in one case, immunosuppressive medication for autoimmune diseases in two cases) and localized disease was reported in three patients. With the exception of one case involving Kaposi's sarcoma, EBV-positive neoplastic cells showed expression of B-cell markers with a non-CGB phenotype (CD10 - , MUM1 +, and BCL6-/+), as our case. Three patients died between 1 and 12 months after diagnosis, one with HPS. Of note, the case reported in the HIV-positive patient involving vascular lumina of Kaposi sarcoma had a plasmablastic immunophenotype but was not tested for HHV8. In that peculiar setting, however, coinfection of the neoplastic B cells with HHV8 cannot be excluded.

To this regard, there are few case reports of HHV8-positive large B-cell lymphoma with intravascular presentation, all occurring in immunosuppressed patients (HIV and organ transplantation) [9-15]. Coexistence of HHV8-positive large B-cell lymphoma with intravascular presentation with Kaposi sarcoma, both disseminated and limited to the skin were described frequently in those cases, as well as co-infection of tumour cells by EBV (62\%). Those cases showed a plasmablastic morphology and immunophenotype (CD20-, MUM1 +). Diagnosis was made at post-mortem examination and all patients rapidly succumbed 2 months or less after of admission to the hospital. Interestingly, cases of polyclonal HHV8-positive circulating plasmablastic cells $\operatorname{IgM} \lambda$ have been described in HIV-positive patients and severe symptoms of muticentric Castleman disease, which may mimick plasmablastic leukemia/lymphoma [16].

The fact that EBV and/or HHV8-positive large B-cell lymphoma with intravascular presentation show varied clinical and pathological presentations, heterogenous outcome and occur in association with immunosuppresion, suggests that these cases are distinct from IVLBCL and rather represent virus-associated large B-cell lymphoma with an unusual intravascular location. Table 2 summarizes the main clinicopathological features of IVLBCL and the virus-associated large B-cells lymphoma with unusual intravascular location.

Other distinctive morphological features in our case were the markedly pleomorphic cytomorphology including Reed-Sternberg-like cells, and the immunophenotype characterized by an attenuated B-cell program, and strong CD30 and PD-L1 expression. To this regard, rare cases of EBV-positive, HHV8-positive large B-cell lymphoma with Hodgkin/Reed-Sternberg-like morphology have been reported, interestingly in HIV-negative patients, but not with an intravascular distribution [9, 17].

This case represents the first report of an EBV-positive large B-cell lymphoma colonizing hepatic haemangiomas. Interestingly, the lymphoma cells were mostly present in association with fibrinous thrombi partially filling the large angiomatous spaces. On a purely histopathological basis, these findings are reminiscent of fibrin-associated diffuse large B-cell lymphoma [1]. In this rare form of large B-cell lymphoma, EBV-positive tumour cells show a latency III program and do not form tumour masses [1]. This B-cell proliferation develops within fibrinous deposits in the walls of pseudocysts, in the cardiovascular system, in cavities, in association with prostheses, or in haematomas [1]. However, in contrast to fibrin-associated diffuse large B-cell lymphoma, our patient presented a profound immunosuppression with a disseminated disease, an EBVassociated HPS and an aggressive clinical course, suggesting that viral oncogenic mechanisms, including latent protein expression (such as LMP1), were determinant for the pathogenesis and clinical course of the disease.

In conclusion, large B-cell lymphoma with intravascular presentation, including IVLBCL, remains a diagnostic and therapeutic challenge due to nonspecific and acute clinical presentation, frequently hindering an early and accurate diagnosis. Those cases associated with viral infection, such as EBV and/or HHV8, present distinct clinical-pathological features and develop almost invariably in the setting of immunosuppression. These findings suggest they correspond to an unusual presentation of immunodeficiency-associated B-cell lymphoproliferative disorders, expanding the spectrum of EBV-positive large B-cell lymphoma. 


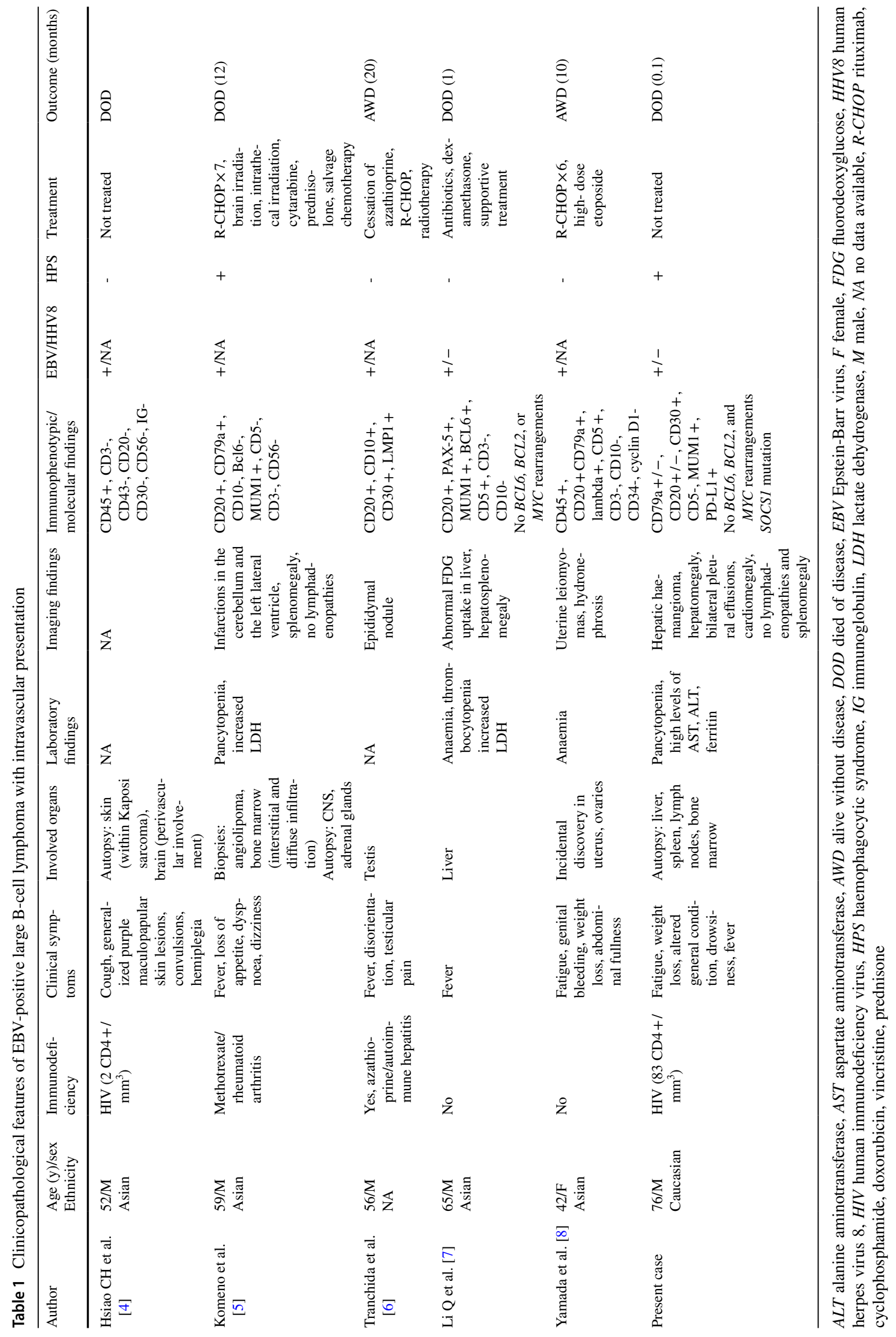




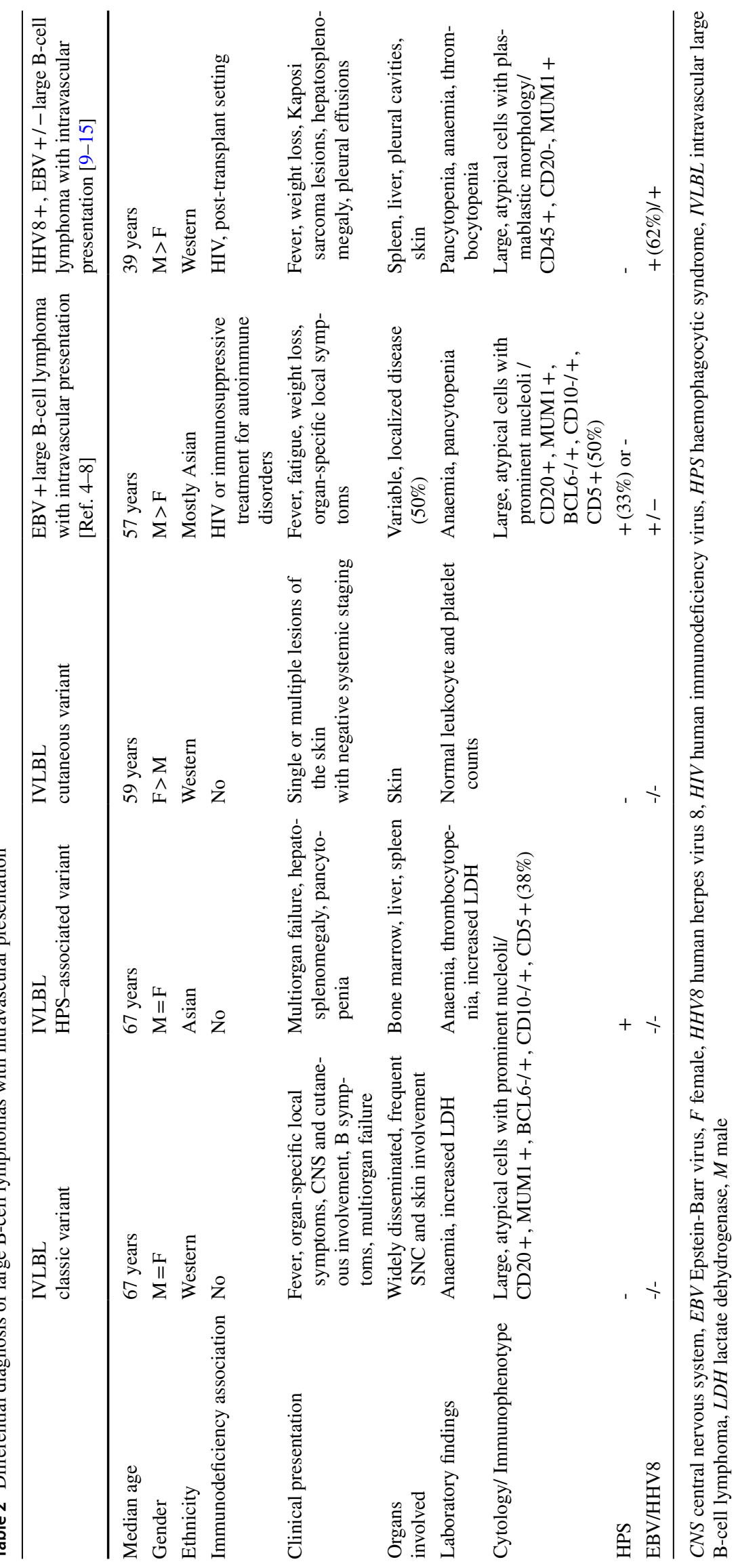


Supplementary Information The online version contains supplementary material available at https://doi.org/10.1007/s00428-021-03142-1.

Author contribution Clinical data information was collected by Pantet Olivier, Alberio Lorenzo, and Cavassini Matthias. Drafts of the manuscript were written by Veloza Luis and Tsai Chun-Yi. Writing, review, and editing of the manuscript were done by Bisig Bettina, Sempoux Christine, de Leval Laurence, and Alberio Lorenzo. Supervision was done by de Leval Laurence. All authors read and approved the final manuscript.

Funding Open Access funding provided by Université de Lausanne.

\section{Declarations}

Informed consent Not applicable.

Consent for publication Not applicable.

Competing interests The authors declare no competing interests.

Open Access This article is licensed under a Creative Commons Attribution 4.0 International License, which permits use, sharing, adaptation, distribution and reproduction in any medium or format, as long as you give appropriate credit to the original author(s) and the source, provide a link to the Creative Commons licence, and indicate if changes were made. The images or other third party material in this article are included in the article's Creative Commons licence, unless indicated otherwise in a credit line to the material. If material is not included in the article's Creative Commons licence and your intended use is not permitted by statutory regulation or exceeds the permitted use, you will need to obtain permission directly from the copyright holder. To view a copy of this licence, visit http://creativecommons.org/licenses/by/4.0/.

\section{References}

1. Swerdlow SH, Campo E, Harris NL (eds) (2017) World Health Organization classification of tumours of haematopoietic and lymphoid tissues, revised, 4th edn. IARC Press, Lyon

2. Ponzoni M, Campo E, Nakamura S (2018) Intravascular large B-cell lymphoma: a chameleon with multiple faces and many masks. Blood 132:1561-1567. https://doi.org/10.1182/ blood-2017-04-737445

3. Murase T, Yamaguchi M, Suzuki R, Okamoto M, Sato Y, Tamaru $\mathrm{J}$ et al (2007) Intravascular large B-cell lymphoma (IVLBCL): a clinicopathologic study of 96 cases with special reference to the immunophenotypic heterogeneity of CD5. Blood 109:478-485. https://doi.org/10.1182/blood-2006-01-021253

4. Hsiao CH, Su IJ, Hsieh SW, Huang SF, Tsai TF, Chen MY et al (1999) Epstein-Barr virus-associated intravascular lymphomatosis within Kaposi's sarcoma in an AIDS patient. Am J Surg Pathol 23:482-487. https://doi.org/10.1097/00000478-199904000-00015

5. Komeno Y, Akiyama M, Okochi Y, Tokuda H, Abe K, Iihara $\mathrm{K}$ et al (2019) Hemophagocytic syndrome-associated variant of methotrexate-associated intravascular large B-cell lymphoma in a rheumatoid arthritis patient. Case Rep Hematol 2019:8947616. https://doi.org/10.1155/2019/8947616

6. Tranchida P, Bayerl M, Voelpel MJ, Palutke M (2003) Testicular ischemia due to intravascular large B-cell lymphoma: a novel presentation in an immunosuppressed individual. Int J Surg Pathol 11:319-324. https://doi.org/10.1177/106689690301100414

7. Li Q, Li J, Yang K, Peng Y, Xiang Y, Sun S et al (2020) EBVpositive intravascular large B-cell lymphoma of the liver: a case report and literature review. Diagn Pathol 15:72. https://doi.org/ 10.1186/s13000-020-00989-x

8. Yamada N, Uchida R, Fuchida S, Okano A, Okamoto M, Ochiai N et al (2005) CD5+ Epstein-Barr virus-positive intravascular large $\mathrm{B}$-cell lymphoma in the uterus co-existing with huge myoma. Am J Hematol 78:221-224. https://doi.org/10.1002/ajh.20288

9. Ferry JA, Sohani AR, Longtine JA, Schwartz RA, Harris NL (2009) HHV8-positive, EBV-positive Hodgkin lymphoma-like large B-cell lymphoma and HHV8-positive intravascular large B-cell lymphoma. Mod Pathol 22:618-826. https://doi.org/10. 1038/modpathol.2009.36

10. Cain O, Yoong A, Lipkin G, Huengsberg M, Murray J, Rudzki $\mathrm{Z}$ et al (2018) Rapidly progressive intravascular primary effusion lymphoma in an HIV-positive renal transplant recipient. Histopathology 72:339-341. https://doi.org/10.1111/his.13347

11. Gwiti P, Jenkins M, Sutak J, Melegh Z (2020) Two cases of rare HHV8-driven intravascular lymphoma with synchronous Kaposi sarcoma, both diagnosed at autopsy in renal transplant recipients. Autops Case Rep 10:e2020206. https://doi.org/10.4322/acr.2020. 206

12. Ashman D, Pantanowitz L (2019) Kaposi sarcoma with coexisting intravascular lymphoma. Int J Surg Pathol 27:62-63. https://doi. org/10.1177/1066896918762053

13. Bruce-Brand C, Rigby J (2020) Kaposi sarcoma with intravascular primary effusion lymphoma in the skin: a potential pitfall in HHV8 immunohistochemistry interpretation. Int J Surg Pathol 28:868-871. https://doi.org/10.1177/1066896920917212

14. Crane GM, Ambinder RF, Shirley CM, Fishman EK, Kasamon YL, Taube JM et al (2014) HHV-8-positive and EBV-positive intravascular lymphoma: an unusual presentation of extracavitary primary effusion lymphoma. Am J Surg Pathol 38:426-432. https://doi.org/10.1097/PAS.0000000000000128

15. Crane GM, Xian RR, Burns KH, Borowitz MJ, Duffield AS, Taube JM (2014) Primary effusion lymphoma presenting as a cutaneous intravascular lymphoma. J Cutan Pathol 41:928-935. https://doi.org/10.1111/cup.12405

16. Oksenhendler E, Boutboul D, Beldjord K, Meignin V, de Labarthe A, Fieschi $\mathrm{C}$ et al (2013) Human herpesvirus 8+ polyclonal $\operatorname{IgM} \lambda$ B-cell lymphocytosis mimicking plasmablastic leukemia/ lymphoma in HIV-infected patients. Eur J Haematol 91:497-503. https://doi.org/10.1111/ejh.12191

17. Sanchez S, Veloza L, Wang L, López M, López-Guillermo A, Marginet M, Martínez A et al (2020) HHV8-positive, EBV-positive Hodgkin lymphoma-like large B cell lymphoma: expanding the spectrum of HHV8 and EBV-associated lymphoproliferative disorders. Int J Hematol 112:734-740. https://doi.org/10.1007/ s12185-020-02897-8

Publisher's Note Springer Nature remains neutral with regard to jurisdictional claims in published maps and institutional affiliations. 